\title{
This Island Manhattan: New York City and the Space Race in The Fantastic Four
}

\section{Matthew Yockey}

Summer 1962, Manhattan. As pedestrians crowd the sidewalks and cars jam the streets, New Yorkers collectively turn their eyes to the sky as a massive object casts a shadow over the city. Deep in the throes of the Cold War, many likely first wonder if a nuclear threat is on its way from the Soviet Union - perhaps the shadow has something to do with Telstar, the communication satellite that was put into orbit on July $10^{\text {th }}$. Surely it isn't another NASA launch; Scott Carpenter just went up in May and the next Mercury mission isn't scheduled until October. Anyway, a NASA flight would not be seen in New York and it certainly would not be launched from the city, as this object, diminishing from sight, must have been. Before it vanishes into the stratosphere there is surely a collective gasp as those below realize just what it is they see escaping the orbit of the city: it is a building.

Many of those on the ground might have been less shocked at the incredible sight if they knew that the structure in question was the Baxter Building, the skyscraper headquarters of the superhero team the Fantastic Four. Indeed, the infamous super-villain Dr. Doom hijacked the building and its fantastic inhabitants, pulling it magnetically with his rocket ship, intent on launching the heroes, building and all, into the sun. If you read Marvel Comics' The Fantastic Four 6 (Sept. 1962) you would also learn that, inevitably, Doom fails in this attempt and is carried away on a passing meteor. The Baxter Building returns to its original resting place in Manhattan, order temporarily restored to the city.

This story, "Captives of the Deadly Duo," is typical of The Fantastic Four of the 1960s; aerial threats to New York City and climactic battles in outer space are central elements. A closer look at the stories produced in the early issues of the comic by

Matthew Yockey is an Associate Instructor and PhD candidate in the Department of Communication and Culture and the American Studies Program at Indiana University. His dissertation examines the role of science and religion in recent superhero films. 
writer Stan Lee and artist/co-plotter Jack Kirby reveals a strong concern for themes typically associated with threats from outer space, or terrestrial threats that the heroes defeat in space. What is particularly interesting about The Fantastic Four is that it stands virtually alone among the superhero comics of its time as a title directly concerned with issues germane to the space race. Certainly other iconic Marvel superheroes of the period had origins in Cold War nuclear anxieties. However, while Spider-Man contracted his powers from a radioactive spider bite and Bruce Banner became the Hulk after being caught in a gamma bomb blast, only the Fantastic Four acquired their super-powers by journeying into space. Significantly, the entire reason they go into space is to beat the Soviets there, locating the very existence of the group as superheroes within a space race context.

Judging by the popular culture of the period (from endless magazine articles about astronauts to soap dispensers shaped like space capsules) Americans were not only consumed by but also consumed the space race. Romantic and exciting representations of space travel permeated the cultural landscape, an indirect extension of the government's attempt to win public support for its costly space program. This program was both a government project and a commodity, the latter functioning to validate the former. In essence the multi-billion dollar program was sold to the public as a two-dollar moon replica piggy bank. It makes sense that comic books would be implicated in this process; what is surprising is how few comics did this to the degree of The Fantastic Four. This comic embraced the space race as a defining narrative trope in its monthly tales of a group of astronautsuperheroes often fighting in and for outer space. These stories in fact were only slightly more fantastic than the advertisements that appeared in many issues. A typical ad for a model rocket appears in issue 30 (Sept. 1964) and features an image of a streamlined rocket poised for lift off. The text promises that the toy rocket will bring "a new world of adventure" and is as "exciting as the space age." A reader could enact his or her own fantasy adventures in space while reading about the Fantastic Four's.

More than just presenting action yarns in outer space, however, The Fantastic Four does something unlike any other comic book of the period: it articulates the concerns of the space race via the mediated site of New York City. Marvel comics of the period are famous for naming New York as the location of their narratives, refusing to create a fictional surrogate city (such as Metropolis or Gotham) that is typical of the genre. The city of Marvel comic books is an actual one, recognizable landmarks apparent throughout the narratives. Beyond this naming, The Fantastic Four does something that no other Marvel title of the time does: it directly implicates the city as a site of national renewal and progress in the race to space. New York becomes a gateway to the stars and, concomitantly, a fortress of democratic ideals that the space race rhetoric of the era claimed it embodied. Raymond Williams contends that in order to effectively perform historical analysis one must consider the dynamic relation among the dominant (present) cultural moment, the residual (past), and the emergent (future). In relationship to The Fantastic Four one can trace how the dominant negotiation of the residual is apparent in the appropriation of Frontier Mythology at the turn of the century, creating a myth of 
the corporation. The frontier myth that defined American identity to that point was incorporated into the rhetoric of industrialism and monopoly capitalism of the period. This resulting corporate mythology intersects with the emergent concerns of the Cold War and the space race in the 1950s and this emergent threat was pacified by its incorporation into the dominant by associating it with the residual of Frontier Mythology. Though here I am focusing only on the first twenty-one issues, this process is strongly articulated in the "classic" incarnation of The Fantastic Four, generally regarded as running from issues 1 (Nov. 1961) through 102 (Sept. 1970).

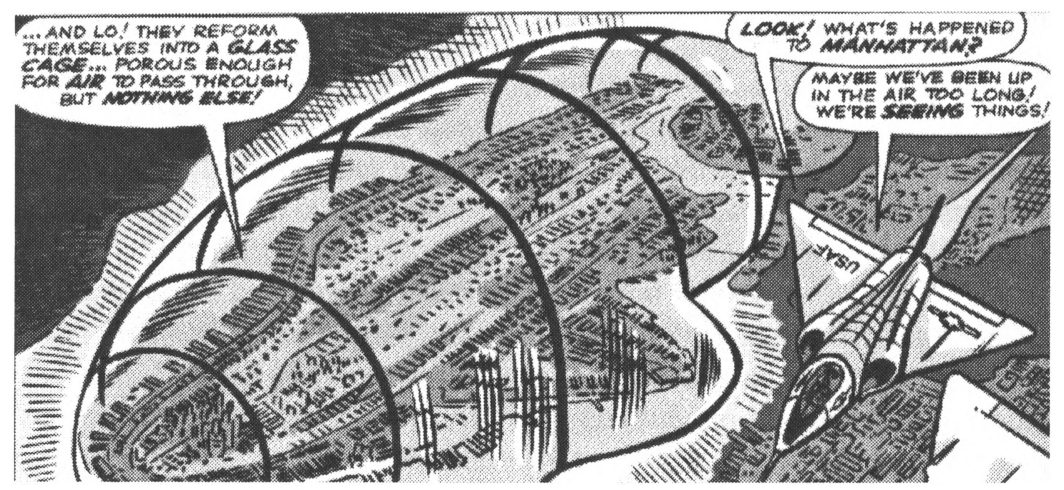

\section{Space is the Place:}

Frontier Mythology romanticizes the rugged individual who represents the nation at large; in this myth personal self-renewal equals national self-renewal. At the end of the nineteenth century, however, this myth was threatened by the closing of the western frontier and the ascendancy of industrial capitalism. By the end of the nineteenth century the American landscape was radically altered by a proliferation of steel-framed bridges spanning rivers and increasingly taller steel buildings that dominated cityscapes. As Cecelia Tichi notes, the designer of these new structures, the engineer, "became the exemplar of technological power and began to appear ... as a new kind of American hero" (105). The hero-engineer remained a constant figure as national mythology accommodated the changing economic and technological landscape of the country. Scientist Reed Richards, the leader of the Fantastic Four, is then part of a tradition of engineer heroes that includes Thomas Edison and the Wright brothers.

The figure of the lone engineer-genius functions in much the same way the frontiersman does: he puts an individual face on national projects of enormous scale. If the frontiersman makes westward expansion and all of its attendant incoherencies understandable, the engineer hero makes the radical transformation of the American landscape comprehensible. Most importantly, the engineer and the structures he produces represent a stabilizing force in a world perceived as increasingly unstable. Tichi quotes New York City Mayor Abram Hewitt, who, at the opening ceremonies of the Brooklyn Bridge, observed that while the bridge 
appeared to lack motion it was, in fact, "instinct with motion ... It is an aggregation of unstable elements . . . The problem was, out of these unstable elements, to produce absolute stability" (105). By being so strongly linked with skyscrapers, the FF represent a potentially destabilizing and destabilized element that can derive stability from the surrounding architecture, as well as restore stability to it. ${ }^{1}$

Similarly, the very products of the engineer are themselves an unsteady element in a national milieu otherwise regarded as constant and natural. How does one accept the presence of bridges that cut ugly swaths across the landscape, or towering office buildings that block out the sky? If Americans see their country as a symbolic new Eden, what does the national mythology do with the presence of the proverbial machine in the garden? The skyscraper contains the answer to the question its form poses within that very form itself. If the world is now experienced as disruptive, then the skyscraper, while potentially emblematic of that disruption, points the way to a new realm of stability, that of outer space.

Robert Romanyshyn contends that the "technological world is a work of reason but of a reason which reaches deeply into dream" (10). Technology is both the cure for and the symptom of mankind's malaise in the newly defined modern world. Within this dynamic, technology offers one both the reason and the means to escape oneself, to recognize a threat to one's very humanity and the means by which one can overcome that threat. Revised Frontier Mythology manifests this transcendence, in that the modified American hero seeks a new personal and national identity beyond the realm of Earth.

Such re-invention is literalized in The Fantastic Four, in which the primary characters are physically transformed by their space trip into superior beings. Their reinvention also indicates their temporal distance from pre-space age America; "the future is now," as the saying goes, which means that the past has been conquered and the newly transformed American is ready to compete with the Soviets in this new era. According to The Fantastic Four, anxious times call for radical changes: Reed Richards' body becomes unbelievably pliable, Sue Storm turns invisible at will, Ben Grimm changes into a powerful, orange monster, and Johnny Storm transforms into a living ball of flame. The group's inherent moral superiority, a trope of the superhero, and their strong patriotism pacify the threat suggested by these technologically-derived changes.

Significantly, their leader, Reed, is an independently wealthy and brilliant scientistengineer working for the good of his country. This is not only consistent with the tradition of engineers as inherently ethical but also works in concert with the growing celebration of industrialized corporate power that began around the turn of the century. Historian Charles A. Beard argues that industrialization was the logical successor to the frontier, its potential for personal renewal as seemingly inexhaustible as America's resources. Beard sees the flourishing member of the industrial state as the natural descendent of the frontiersman and the farmer. Furthermore, within an industrial society companies naturally compete with one another for market dominance; productivity, not monetary gain, is the final arbiter of success. This reclamation of national mythology transforms the frontier from a material, geographical realm to an abstract, immaterial one in which physical exploration becomes technological innovation, mar- 
ket dominance the spoils of the victor.

Advances in space technology, however, render this valorization of corporate America problematic, for, beginning in the 1950s, outer space becomes a potential new frontier for national expansion. How does the mythology that had evolved in a post-frontier context suddenly readjust and accommodate a newly acquired frontier? This is primarily achieved when Americans perceive this new frontier in the same way they saw the original one, as a simultaneous source of renewal and threat. Indeed, with the launch of Sputnik in 1957, Americans regarded a national space program as imperative to national survival. Once again, the threat of technology demanded a technological response. If the American frontier was officially deemed closed in the census of 1890, it was logical that Americans would project the concerns of Frontier Mythology onto the stars as soon as the threat of mass destruction from both terrestrial and extra-terrestrial points emerged in the national psyche. These concerns are entwined with corporate enterprise, so that the nation's project of self-determination embodies both the space race (the new physical frontier) and market dominance (the already established immaterial frontier). However, because the space race would require vast amounts of funding and public support, the U.S. government had to take a technically complex endeavor administered by bureaucrats and managed by engineers and make it both understandable and desirable to the general public. Fear-mongering and patriotic appeals in the popular media became the most effective avenue for this. Lee and Kirby's comic was not the only cultural text performing this work. However, in its condensation of the space race, the city, and corporations, it is a unique artifact that addresses multiple concerns of the period in complex ways.

\section{Fantastic Frontiers}

The Fantastic Four was not the first time popular culture narrated a national space fantasy (beginning in the 1920s pulp fiction magazines featured space narratives). However, the mainstream public's interest was not fully engaged in a space program until the issue was placed within the context of the Cold War. With the Soviet Union's launching of Sputnik 1 and Sputnik 2 in 1957 space exploration suddenly no longer seemed a whimsical scientific luxury but a pressing national emergency. The rhetoric of space travel quickly took on dire tones and the possibility of Soviet control of space inspired the creation of the National Aeronautics and Space Administration (1958) and the space race of the 1960s that culminated in the moon landings of 1969-1972.

Attendant to the promotion of the space race as a national concern was the construction of the astronaut as a heroic figure, cut from all-American cloth and ready to outperform his Cosmonaut counterparts. Howard E. McCurdy notes that by "promoting the astronaut corps, (NASA was) . . . able to reduce complex technical issues to personal values such as bravery and patriotism"(88). Media attention on the first contingent of American astronauts (the "Mercury Seven") was intense; Life magazine, which held exclusive rights to each astronaut's first-hand stories, alone dedicated articles to them in twenty-eight issues from 1959 to 1963 (McCurdy 88). 
By promoting the image of the competent and heroic American male at the helm of a spacecraft, NASA also promoted the proxy image of the heroic engineers and scientists who were responsible for the creation and execution of the program on the ground (The Fantastic Four conflated those roles into the figure of Reed Richards). Not only did the American public then have a new frontier and frontiersman to promote national ideals, but also an image of science and technology as a national boon, thus pacifying some of the technophobia of the Cold War. The ability to explore space mediated the threat of global annihilation by nuclear warfare. While the space program was inherently dangerous to the astronauts, to not pursue it was perceived as potentially even more dangerous to the national body. The race to the moon inaugurated by President Kennedy on May 25, 1961 became a national enterprise, validated by television broadcasts of launches and returns, and the overwhelming presence of space rhetoric in popular culture.

Engineers and astronauts could not win the race to the moon alone, however. They merely stood at the vanguard, helming an enterprise in which all Americans theoretically had a stake. In a speech delivered at Rice University on September 12, 1962, President Kennedy laid out his ambitious space plans for the country, linking the project of a moon landing with core democratic values that define America. Invoking Frontier Mythology, he said, "This country was conquered by those who moved forward - and so will space" (Nevins 242). More than this, though, he warned that America's failure to fully engage in a space program would lead to dire consequences, not just for the U.S. but for the world at large: "[N]o nation which expects to be the leader of other nations can expect to stay behind in this race for space... For the eyes of the world now look into space, to the moon and to the planets beyond, and we have vowed that we shall not see it governed by a hostile flag of conquest, but by a banner of freedom and peace" (Nevins 243). To support the space program is to support freedom and peace, to oppose it is to allow cruel dictatorship from the skies. The space program became, under Kennedy, the defining national cause of the decade. Its symbolic cache only grew as those other ambitious national projects of the decade, Lyndon Johnson's "Great Society" and the war in Vietnam, failed to satisfy the need for national regeneration in uncertain times.

\section{The Place is Space}

If both the Kennedy and Johnson administrations were heavily invested in winning public support for the space race, and popular culture was a primary tool in this endeavor, it is essential to consider how The Fantastic Four, the most scientifically-oriented superhero comic of the time, engages in this rhetorical battle for American hearts and minds. It is important to first lay out the historical and symbolic significance of New York City's skyscraper architecture leading up to the 1960s to better contextualize an understanding of how the comic works to embrace national space goals within an urban context, for what is ultimately at work in The Fantastic Four is a re-inscription of American citizenship by way of New York City. The city becomes the metonym for the nation, so that the latter's concerns are condensed within the space of the city. If the Fantastic Four are ideal American 
patriots, then the comic's rhetoric compels one to regard the city to which they are so strongly linked as the ideal American space.

In their exhaustive study of New York City architecture, New York 1960, Robert A.M. Stern, Thomas Mellins, and David Fishman write that before World War II,
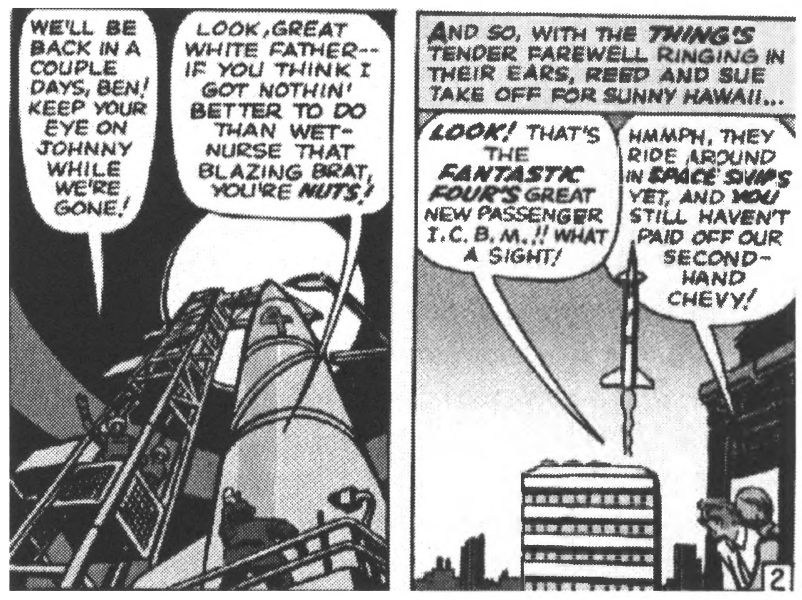
"metropolitan New York was both a miniature and a distillation of America ," a model of "the country's pluralist, democratic society" (8). In all its congestive, skyscraping glory, New York came to embody the push and pull of modern society, its constrictive boundaries and the limitless potential implied by its soaring verticality. New York was the site of promise, the city of the future. In his 1929 book The Metropolis of Tomorrow, architect and artist Hugh Ferriss renders a fantasy vision of New York that captures this dynamism. Ferriss' charcoal depictions of mistshrouded, towering, and indistinct skyscrapers represent a vision of the city as a new Athens. The dream-like rendering of this city of the future is as significant as the civic ideals such a comparison invokes. As Rem Koolhaas observes, "Ferriss' most important contribution to the theory of Manhattan is exactly the creation of an illuminated night inside a cosmic container, the murky Ferrissian Void: a pitch black architectural womb" (117). In the vision of Ferriss, Manhattan is equally a city and an island, a pocket of progress upon which desires can be projected. The city becomes the location of ideals that define and transcend the nation, a utopian space that invokes an imagined past as it envisions an imagined future, in the process creating an imaginary present. Importantly, the city achieves this symbolic station by being removed from the rest of the country. It exists in an idealized space in the American imagination, at once symbolically American but not actually America. In The Fantastic Four Lee and Kirby depict a Manhattan that equally represents a simultaneously known and unknown entity to their readers.

Such visions of cities are prevalent in science fiction. Janet Staiger notes that in science fiction films "readily distinguishable sections of today's cityscape are present while other parts are rewritten" (97). In terms of New York, when one pictures the city as utopian this rewriting tends to serve a modernist aesthetic that valorizes monopoly capitalism. The tension between residual Frontier Mythology and the dominant corporate culture of modernity produces a fantasy emergent, the utopian city. Corporate culture, the modern location of the self-renewing ideas of Frontier Mythology, is where the individual citizen and the nation as a whole regenerate and affirm identity, where the American Dream is manifested. It is where the 
residents of the city enjoy seemingly limitless material luxuries, the defining goal of the new, corporatized American dream.

An idealized image of New York is evident throughout The Fantastic Four. Lee and Kirby represent the city as a utopia contained within a four-colored "Kirbian" womb, a discrete space that embodies the democratic ideals of American society. According to Koolhaas, the Ferrissian Void that Manhattan exists in is a womb in which the city's architecture "absorbs multiple impregnation by any number of alien and foreign influences ... (that) ... . are effortlessly accommodated in the expanding receptacle of Ferriss' vision" (117). Kirby's vision of Manhattan is a womb equally accommodating to penetration because the corporate culture that has already sown its seed there is able to assimilate influences. Kirby's Manhattan is a resolute corporate space in which the architecture reflects the ideology of modern capitalism in its machine-like surfaces. If, as Le Corbusier famously said, a house is a machine for living, Kirby depicts Manhattan's skyscrapers as machines for working and defending America. As the series progresses his drawings of Manhattan become more abstract and intricate, increasingly marginalizing the mundane and ordinary, and more fully integrate the strip's fantastic beings with their manufactured landscape. In depicting, for example, the planet-draining machinery of Galactus in issue 49 (Apr. 1966), Kirby figuratively externalizes the machinery inside the Baxter Building. By symbolically turning the Baxter Building inside out, the comic acknowledges anxiety about the corporatized scientific work Reed does inside the building. In presenting the spectacle of the FF defeating the externalized alien threat, the comic also pacifies those anxieties. The scientific industry of corporate America, is, like the space program, with its televised launches and moon landings, a spectacle that affirms American progress and superiority.

Invasions of the city come from above and, occasionally, from below, but those threats are never regarded as a product of the corporate capitalism that characterizes the city. Indeed, corporate power is rendered as the source of the city's protection, a benevolent force, embodied by the Fantastic Four, which works for the good of all New Yorkers and, by extension, all Americans. According to Thomas Bender and William R. Taylor, "in the history of urban form in New York horizontal monumentalism implies civic or public purpose, while the tower represents the power of corporate capitalism" (190). In the mythology of the corporate frontier, the skyscraper embodies the national heroic, appropriating the symbolic power of the horizontal civic buildings and monuments.

The architecturally bland corporate skyscraper began to dominate the Manhattan skyline after World War II. Because of economic efficiency, modernism was the style of choice in the skyscraper boom of the 1950s, characterized by corporate skyscrapers such as Lever House (1952), and the Seagram Building (1958), "a tower built to elucidate the ... principles of order, logic, and clarity in all things" (Goldberger, 112). This latter building ushered in an entirely new era of modernist skyscraper in the 1960s; following a change in zoning laws in 1960, Manhattan erupted in a rash of "sheer tower[s] . . soaring straight up from an open plaza" (Goldberger 115).

Manhattan seemed to experience and express the post-war economic boom more intensely and directly than the rest of the nation; again New York was the emblem- 
atic city. While the boom produced extravagant symptoms such as the skyscraper, these very characteristics became symptomatic of much that many regarded as threatening in this boom period. The changes in New York that occurred in the 1950s and 1960s are an extension of the general anxieties wrought by modernity and many regarded the city as a place at once at the center of the world and perpetually threatening to "spin out of control" (Stern 19). In addition to increased car congestion in the city, the changing racial make-up of its citizens informed this perceived loss of control: "During the 1940s and 1950s, 1.2 million whites moved out of the city ... At the same time, the city benefited from an influx of southern blacks and Puerto Ricans. By November 1957 New York would become the first city in the world to have a black population of more than one million" (Stern 15). Hegemonic order prescribes American identity within white, middle-class boundaries. So, while the skyscraper as emblem of corporate America affirmed hegemonic order, those on the ground who fell outside its boundaries perpetually challenged this order. The fact of white flight from the city center lends further symbolic cache to the city's new skyscrapers. By extension, if the nation at large seemed rent by racial strife, one could always look at the Manhattan skyline for affirmation of the status quo.

In these early years of The Fantastic Four, the city is rendered as purely white. The sign of corporate power becomes the emblem of the white superhero team, defending American liberties in the face of alien hostilities that come from above and below and represent white middle-class fears of ethnic American and Soviet threats. Skyscrapers are as white as spaceships in the 1960s. The primary occupant of the skyscraper, the white corporate male, is mirrored by the sole occupant of the 1960 s spaceship. If cities contain emblems of corporate hegemony in the form of skyscrapers that exist in tension with racial "invaders," the spaceship represents a more extreme version of the skyscrapers' verticality. Of course, the space program in the 1960s was equally invested in maintaining a strict racial hierarchy. The program was a vehicle of a nationalism that, by definition, excluded those who were not regarded as traditionally part of the nation. NASA was able to render an exclusively white (and male) vision of America that resonated with essential conceits of Frontier Mythology, actualizing the rhetorical work of the skyscraper. If corporate headquarters could only strain towards the sky, NASA could devise a "skyscraper" (that is, an emblem of white corporate power) that could actually explore that new frontier. As Lynn Spigel notes, "[T]he racism of space science went hand in hand with the racism of housing, community planning, and transportation back on earth ... Whether in the mundane streets of suburbia, or through the fantastic voyage to the moon, whites secured their power through the colonization and control of space" (145). As another product of white corporate America, The Fantastic Four uncritically duplicates the silently racist ideology of the space program, conflating it with the similar rhetorical function of Manhattan's corporate skyline. As a result, in its early years the comic admits little to no space for ethnic or racial minorities except through the reductive symbolism of generic alien threats. In the Manhattan of the Fantastic Four there is no white flight from the city center because there is no ethnic other to flee from. The core of the city is not only resolutely white but it becomes the center of this white America, the heart of democ- 
racy and freedom, the hub of the world. The Fantastic Four exist in a utopian Manhattan of white, middle-class New Yorkers who can afford to constantly look up at the battles overhead because there is no crime on the streets to distract them. This utopian vision erases the typical problem of the superhero city; the Fantastic Four never have to concern themselves with muggings or bank robberies. Their

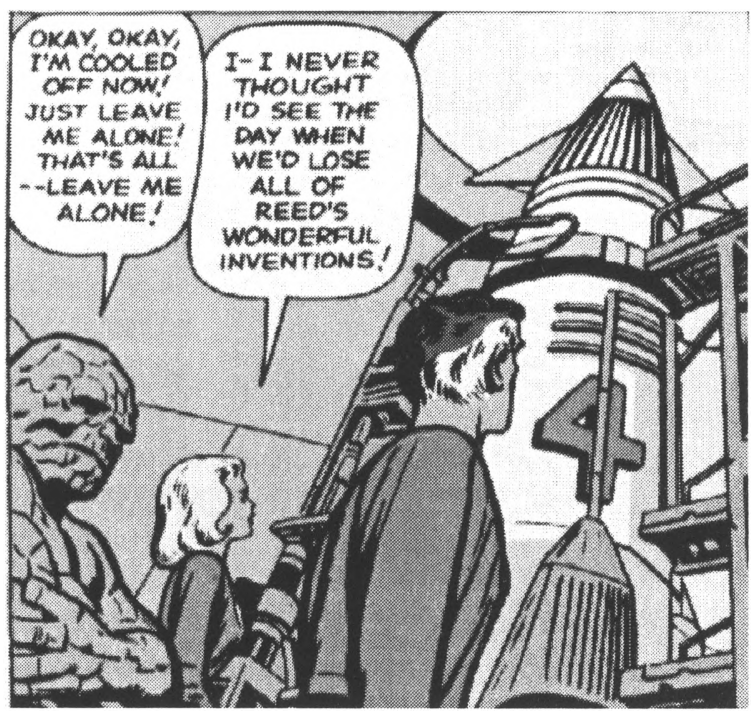
agenda is much more important: the defense of the free world.

The comic book offers a conservative vision of the present that resonates with an imagined glorious past as it suggests a paradisiacal technological future. From its first issue, The Fantastic Four takes Kennedy's call to arms to heart, firmly grounding its narrative in patriotically inflected space age rhetoric centered in New York City. While the purpose of their trip into space is not clearly stated (in issue 2 Reed says it was a mission to Mars but this possible objective is never mentioned again), their urgency to get there is underscored by Sue's plea to a reluctant Ben before the mission: "Ben, we've got to take that chance ... . unless we want the commies to beat us to it!" Garbed in classic astronaut gear inside a prototypical silver rocket, the soon-to-become Fantastic Four are equipped technologically and ideologically for the rigors of the space race. And while Ben's initial fears seem validated by their subsequent transformations ("You know we haven't done enough research into the effect of cosmic rays! They might kill us all out in space!"'), it is significant that the dangers of space also present the FF with an opportunity to even more effectively defend American interests as a superhero team. From the first issue on, Lee and Kirby exploit the appeal of characters that simultaneously represent anxieties about space travel and pacify such concerns.

They also defend "a way of life," for both the skyscraper and the space program are strongly rooted in the mythic American concern with frontier. Americans became increasingly anxious about the future after World War II, regarding the Soviet Union as a threat both to the American way of life and to American lives. As a result American popular culture further idealized the future and the past. The technological world that contributed to a sense of displacement and anxiety mediated a superficial denial of contemporary unease about the future. What results is a conflicting, neurotic relationship regarding technology and the future. This neurosis strongly informs and motivates the narrative of The Fantastic Four, in which the city suffers 


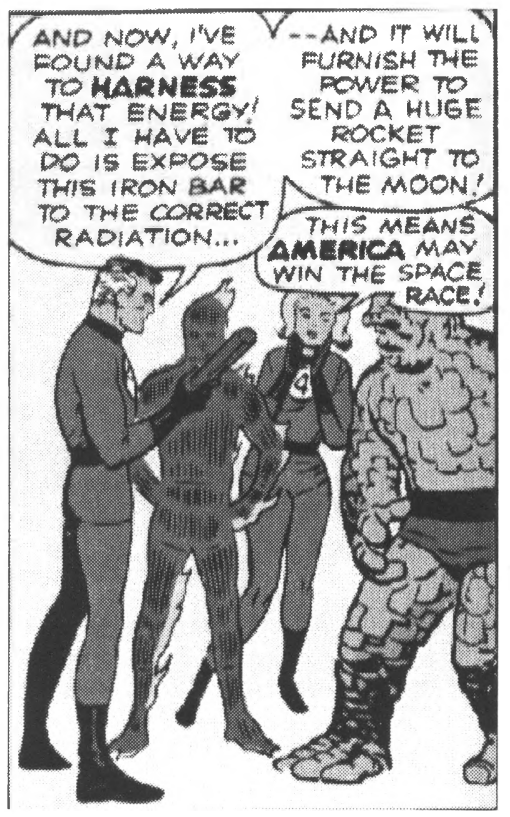

from perpetual attacks by super villains and invasions by space aliens. Indeed, the seriality of the monthly comic and the repetitive nature of its narratives are further manifestations of this neurotic apprehension of modern concerns. The comic perpetually enacts an invocation and suppression of anxieties informed by the tension between the American imagination (based on an imagined glorious past of Manifest Destiny) and American reality (in which destiny seems to play no part).

Issue 7 (Oct. 1962) foregrounds the conflation of national concerns with those of the FF. In this issue, Kurrgo of Planet X sends a robot to Earth to kidnap the FF so that Reed's scientific knowledge may save Kurrgo's race from a "runaway asteroid." As his ship approaches Earth "one of America's new eye-in-the-sky satellites . . . flashes the word to command headquarters below."

The next panel shows army brass wondering if the spaceship might portend "an attack by the reds." That the menace to the FF from outer space is considered a possible Soviet threat suggests not only a symbolic link between the two but also that only the FF can recognize and ultimately defeat the extra-terrestrial threat. Of course if the FF did not exist, Kurrgo would not even have invaded the earth, again indicating the fundamental tension of technology that simultaneously produces and mediates threats to the world. Earth-bound technology is in two important instances here affiliated with the "good guys," i.e., America. In the first instance we see an American satellite benignly monitor the skies for such things as hostile spaceships. The second instance is the FF themselves, their vaunted status as technological and ideal Americans highlighted by their invitation to a Washington, D.C. dinner in their honor. Space is the place where threats to America reside, but also where American ideals can be fully realized in response to those threats. If Kennedy invoked the possibility of Soviet domination from outer space, The Fantastic Four simply extrapolates that menace to beings from other planets, a fantastic nemesis juxtaposed against these equally fantastic urban Americans.

Paul Goldberger observes that the New York City skyscraper "symbolized at once the power of technology and the power of history - or, to put it another way, they expressed the belief of their corporate owners and tenants that an adaption of the new technology did not have to mean an abandonment of tradition" (37). The city in The Fantastic Four becomes an imagined past and future site of white utopia. People were able to at once deny the peril of the future and endorse its potential benefits by embracing a depiction of a national past romanticized within a technologically advanced medium. This also pacified another hazard brought on 
by technology, that of a more democratic society. It is important then that the Fantastic Four not only resides within a corporate skyscraper, but that their headquarters are at its very top, distancing them from the hoi polloi the comic depicts almost exclusively as white and middle-class. The Fantastic Four remains blissfully unaware of any class, ethnic, or racial divisions that existed in the real New York. Lee and Kirby's utopian depiction of the city completely elides the civil unrest that increasingly gripped other metropolitan areas during the decade (such as the Watts riot of 1965 and the Detroit riot of 1967). Here the comic locates class strife exclusively as comic relief, often in the guise of the unseen Yancy Street Gang, a group of white men whose taunting of the Thing establishes an interesting tension between these implicitly working-glass men and the working-class inflected Ben Grimm. As the one member of the FF who cannot control his powers or identity in that he is always the Thing, Ben's association with New York working-class culture is further evidence that the comic regards this culture as less amenable to the responsibilities of super-citizenship in the space age. The fundamental narrative conflict between Ben and Reed is emblematic of the comic's attitude about class in this context. Of further interest is the fact that Stan Lee has said that he derived the name Yancy Street from Delancy Street in New York's Jewish Lower East Side. Given that Ben Grimm has been identified in recent years in the comic as Jewish and that both Lee and Kirby were Jews, the implication that the Yancy Street gang is Jewish adds another dimension to the comic's class consciousness.

A striking example of the class division within the group that echoes similar division within the city occurs in issue 18 (Sept. 1963). A brief sequence at the beginning of the story depicts Reed and Sue donning space suits to go swimming. An incredulous Ben (wearing street clothes that mark him as part of ordinary New York) asks, "Well, why the junior spaceman get-up? They got swimmin' pools on the moon!?" Reed explains that they are going to Hawaii in an "experimental passenger I.C.B.M." As their rocket lifts off from the roof of the Baxter Building, we see a couple watching from the window of their apartment. Significantly, the apparatuses of the FF are not only instantly recognizable but sources of consumer envy that bring to the surface the physical and economic distance between the average New Yorker and the Fantastic Four, especially Reed Richards. However, the comic tone of this moment pacifies any suggested critique of class division. New Yorkers are sources of amusement, promoting the suppression of social critique, displacing national concern onto I.C.B.M. missile trips to Hawaii by ultra-rich superheroes. Ben's exchange with Reed echoes the humor and class-tension of the final panel, particularly when he addresses his leader as "great white father."

When the comic depicts rampant anarchy in the streets of the city in issue 21 (Dec. 1963), the FF discover that a masked villain called the Hate Monger has used mind control techniques to sow civil unrest. The fact that he is revealed at the story's end to be none other than Adolph Hitler further distances the narrative from any connection with contemporary issues and allows the Fantastic Four to retroactively participate in World War II. The story in issue 35 (Feb.1965), "Calamity on Campus," suggests that the Fantastic Four might encounter the nascent youth counterculture of the era. However, when they arrive at the campus of "State U.," 


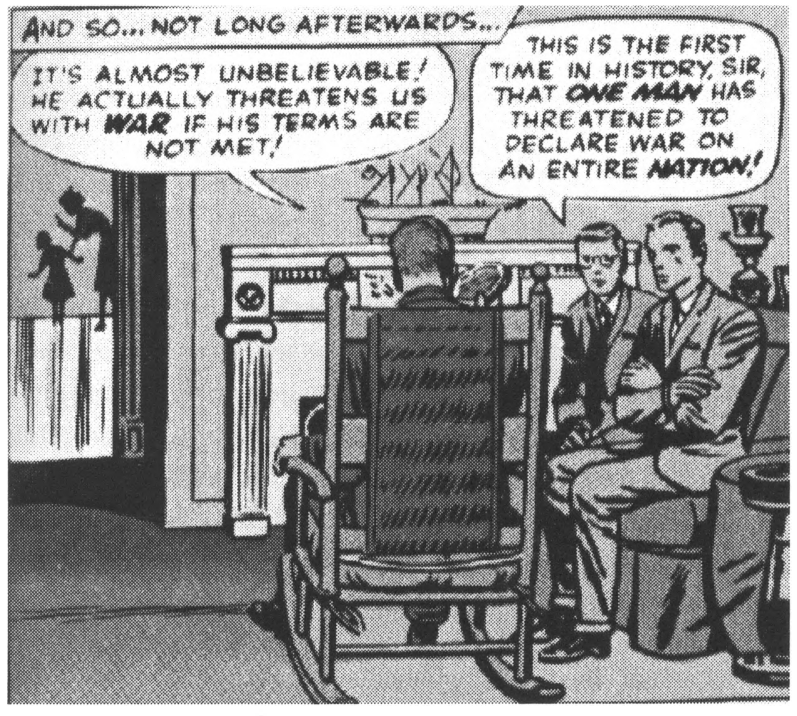

well-groomed, white students seeking autographs mob them. The "calamity" turns out to be a robot "Dragon Man" controlled by the villain Diablo.

The cover image of the first issue (Nov. 1961) firmly represents the city under threat and the FF as its potential rescuers. Of note in this origin story is how, until their identities as superheroes are firmly established, the FF themselves

frighten and intimidate their fellow citizens. However, in subsequent issues Lee and Kirby very quickly establish a close relationship between the FF and their fellow New Yorkers, while also maintaining a distance between the two groups. Therefore, the FF does not adopt secret identities, nor wear masks as part of their costumes. This unique break with superhero conventions simultaneously foregrounds the FF's identities as "real" people and their distance from the average citizens who remain steadfastly earth-bound. The comic denies the common trope of the secret identity, that either the superhero or "civilian" self is a disguise, that the hero is fundamentally bifurcated. In The Fantastic Four the superheroic self and the "real" self are the same, the implied superiority of the superhero utterly naturalized.

What then is the necessity of a superhero name at all? Indeed, throughout the comic the four are as often referred to by their given names as their superhero ones, regardless if they are wearing their uniforms or street clothes. In this comic one of the functions of naming is to further emphasize the gulf between the ordinary and the extraordinary in this world. As noted earlier, Reed is the consummate heroic engineer and, while Ben is originally brought into the group for his piloting skills, Reed is more representative of the heroic astronaut figure of the time. Ben himself is ultimately too ordinary in his character (or perhaps too Jewish) to correspond to the ideal American that the original NASA astronauts represent. Ben constantly needs Reed's theories and explanations translated into plain English, but what clearly demarcates the two other than intellect are their powers and their names. Reed is Mr. Fantastic, able to stretch his body in nearly unlimited ways, while Ben is the Thing, a rocky monstrosity who can punch his way out of any prison but the body he is trapped in. Reed is the consummate modern man, his pliability suggesting the infinite reaches of space, while the Thing is resolutely pre-modern in appearance and reach. Throughout the comic it is Reed who explores new dimensions and tests different ways to reach the stars. He looks as comfortable in a space 
helmet as the Thing looks uncomfortable in his orange hide. This division between Reed and Ben is extended in the Thing's relationship to more terrestrial concerns, such as his non-super powered girlfriend Alicia and the Yancy Street Gang. Reed represents the heroic potential of the engineer-astronaut condensed into one figure, superior to, but also representative of, the average American.

Average Americans are represented in the comic beyond the nameless faces in the crowded streets. The comic defines the FF's elderly postman Mr. Lumpkin, one of its earliest continuing "normal" characters, as utterly non-superheroic. This intermediary between the FF and the rest of New York/America hauls mountains of fan mail to the Baxter Building and constantly asks to join the FF, showing off his "power" of ear wriggling. In issue 11 (Feb. 1963) Reed responds to Lumpkin's appeal by patronizing him, saying, "We're all filled up right now, Lumpy, but we'll keep you in mind, old timer!" Sue then activates the FF's exclusive (i.e., corporate) elevator and the group leaves the masses down below. This encounter with the mailman follows a scene in which the FF interact with children who are dressed up as the Fantastic Four on the streets. This sequence further infantilizes New Yorkers and again suggests that they primarily regard the FF with equal degrees of admiration and envy.

The second issue (Jan. 1962) represents a tentative step towards a more spaceoriented narrative. Here the villains are a race of shape-shifting aliens, the Skrull, who attempt to invade Earth. In the earliest example in the series of the conflation of city space and space-age technology, the Skrull's spaceship is a disguised water tower that lifts off from the roof of a city building and which later returns the FF to Earth.

Issue 3 (Mar. 1962) remains Earth-bound but further foregrounds the city as an essential component of the comic's milieu. Issue 1 identifies the setting as the fictional "Central City," a name only invoked this particular instance. While issue 3 does not name the city as New York (this finally occurs in issue 4), it begins to take on more definite features, introducing the group's "secret headquarters" within this urban landscape. Kirby provides the first drawing of what will later be named the Baxter Building, a detailed, cut-away diagram of the many components of their headquarters, including a missile monitoring room, pogo orbit plane hangar, and a long-range passenger missile. There is also space allocated for living quarters, indicating that the group has successfully integrated the domestic and work spheres, dedicating themselves to the defense of humanity/America as fully as the American military and space program. Additionally, as with the elimination of secret identities, the lack of secrecy about the group's headquarters emphasizes their elite status within the city while creating a sense of intimacy with the rest of New York. It is this intimacy that allows the Yancy Street Gang to play practical jokes on the Thing but also admits to the vast superiority of the fantastic group to average New York. Again, they do not have to hide their identities or their headquarters because the only "threat" from the city itself might be a Beatle wig mockingly sent to the Thing. Generally speaking, all is well on the streets below the FF. Their primary concerns are alien threats to that well-being, usually from above.

Issue 4 (May 1962) again keeps the action on Earth, but by this point in the comic Lee and Kirby firmly establish one of the primary images of the series, that of the FF gliding over the buildings of Manhattan in their Fantasticar. Whether by way of 
this car or similar flying vehicles designed by Reed, or in the use of a flare gun to signal one another, the skies are clearly the domain of the FF, their near-constant presence in it suggesting its significance as the city's most important border. Issue 5 (July 1962), which introduces their arch nemesis Dr. Doom, is equally important in that we see the first example of the FF being attacked by way of the building they occupy, further conflating their identities with their work and living space. Issue 6 establishes yet another trope to become commonplace in the title, that of New Yorkers reacting on the street to the spectacle of the Fantastic Four above (several pedestrians respond to the sight of the Human Torch weaving between buildings). As noted, it is also in this issue that the Baxter Building is literally made a spaceship. The story concludes with an image of the building returning to earth, accompanied by this caption: "[T]he stray individuals who later witness the silent return of the Baxter Building from the skies write it off as a bad dream ... an hallucination resulting from the anxieties that plague our nuclear society." The world of the FF is simply too incredible for the average Manhattanite to fully comprehend, and the only way to accommodate it is to locate it within the context of the Cold War.

Issue 17 (Aug. 1963) represents the FF as the embodiment of American ideals, though here they do not simply outperform the United States military, but the president himself. In this issue Dr. Doom threatens the U.S. with war if his demand for power is not met. Curiously, his modest condition is to be given a cabinet post in Kennedy's administration. This allows for a two-panel sequence in which JFK discusses Doom's ultimatum with a pair of advisors, Jackie and Carolyn silhouetted in the background. Kennedy decides, "There is only one thing to do! We must show him that the United States cannot be threatened by anyone! We must move forward and proceed with great vigor! And now, gentlemen, if you'll excuse me, it's Caroline's bedtime!" The leader of the free world is strangely passive, his rhetoric of "vigor" notwithstanding. Duplicating the dynamic of the space race, it would seem that it is the President's job to clearly articulate the nation's agenda, while it is the duty of its best and brightest citizens to meet those stated goals. Because the President does nothing more than tuck his daughter in bed, Doom attacks the United States the next day. He sabotages factory machinery and the nation's defensive missile systems and a caption tells us that "almost overnight, the mighty industrial complex of America seems to grind to a halt!" Finally the Joint Chiefs of Staff calls on the FF to defeat Doom so that control of the nation can be restored.

If JFK is not always an actual presence in the comic, he is usually a rhetorical one. Lee and Kirby focus on the race to the moon in issue 13 (Apr. 1963), which was on newsstands a few months after Kennedy's speech at Rice University. In this issue Reed tells the team that he has discovered "a booster fuel powerful enough to enable us to catch up with the reds in the race to the moon!" In a show of American democracy, zeal, and self-sacrifice, the rest of the group demand that they accompany Reed on what he planned to be a solo mission ("I can't ask you to risk your lives with me!" he feebly implores them). Meanwhile, "behind the Iron Curtain," the Soviet scientist Ivan Kragoff is also about to launch a ship to the moon. However, instead of a crew of patriotic countrymen, Kragoff is accompanied by a less impressive coterie of "comrades": a baboon, gorilla, and orangutan that he has trained to 
help him on his mission "to the moon-to claim it for the Communist empire!" Kirby lays out the next page as a panel for panel duplication of the simultaneous launches. Kragoff and his simian partners pass through a cosmic ray storm that endows them with super-powers and, interestingly, it is unclear which rocket lands on the moon first. However, when the FF land they meet the Watcher, a benign alien who spends his time simply watching events on Earth, following the prime directive of his voyeuristic race to never get involved with the affairs of the planet he observes. He temporarily suspends this rule since the moon is his domain and he sees the FF and Kragoff's landing there as a violation. His resolution is to have the FF battle Kragoff for bragging rights to the moon amidst the ruins of an ancient Lunar civilization. Inevitably the FF prevail and the Watcher leaves them with these words, "Space is your heritage-see that you prove worthy of such a glorious gift!" While his words are directed at all of humanity, they are spoken to Reed, who is shown in dramatic profile, indicating that the moon has fallen into the "right" hands and that the Soviets are illegitimate claimants to this "heritage."

With the race to the moon decisively won by the FF, it would seem the comic would have nowhere else to go but up after this, which is exactly what happens. While maintaining the Baxter Building as a base, the FF spend the rest of the 1960s exploring the furthest reaches of space, exemplified by Reed's trip to "sub-space" in issue 51 (July 1966), in which he exclaims, "I've done it!! I'm drifting into a world of limitless dimensions!! It's the crossroads of infinity - the junction to everywhere!" That the "junction to everywhere" can only be reached by a wealthy white scientist from the top of his Manhattan skyscraper headquarters is, by this point in the title, accepted as a natural condition of the world. After their conquest of the moon, The Fantastic Four depends more directly on the Baxter Building as both a launching pad to other galaxies and dimensions and the target for alien invasion and super villain attack.

All the while, Reed remains emblematic of the hegemonic order the FF defends and he is often mirrored by the super villains the group fights. Victor von Doom was a brilliant science student at State University with Reed who was injured and driven insane by a lab accident. He adopts the name Dr. Doom and uses his scientific knowledge to wage war on the world. It is significant that Doom's given name suggests German ancestry, invoking the

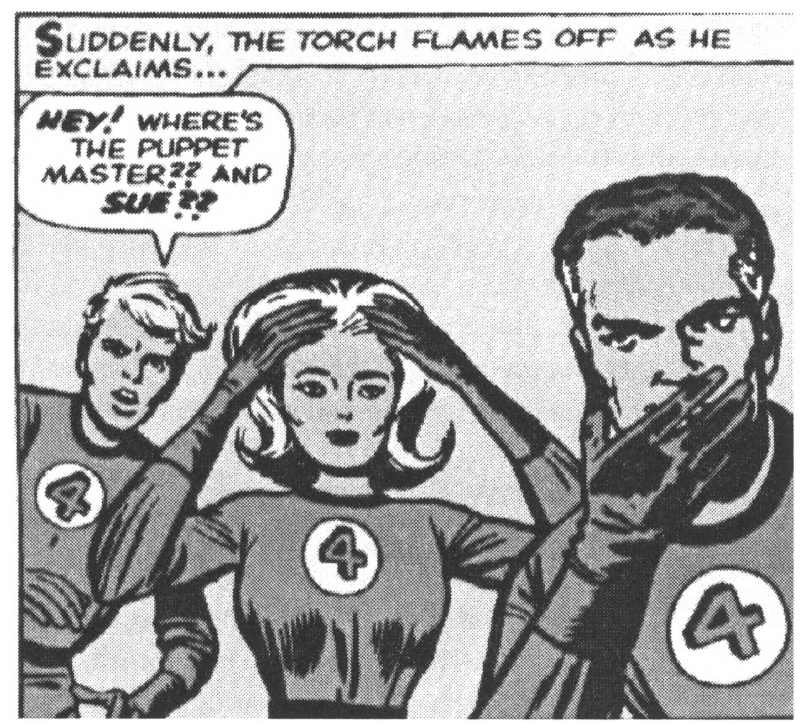


Nazi rocket program headed by Wernher von Braun. Though von Braun worked for the U.S. government following the war, The Fantastic Four makes no such space for an ambivalent accommodation of the former enemy. In the comic Doom is resolutely European (he is the sovereign head of "Latveria") and irredeemably evil. As the negative image of Mr. Fantastic, Doom is ideally suited as the group's primary nemesis. Similar mirroring occurs in issue 20 (Nov. 1963). This story is about a lowly lab technician for Acme Atomic Corporation who injures himself in a lab accident. As a result he gains the ability to control inorganic molecules. He dubs himself the Molecule Man and terrorizes Manhattan by tearing the Baxter Building from its foundation and levitating it over Times Square. When the FF tries to stop him he manipulates the city into revolt against them. Sidewalks, bricks, underground pipes, water towers, electricity, and even newspapers at a newspaper stand attack the heroes. To eliminate the hope of outside rescue, the Molecule Man creates a glass bubble that surrounds Manhattan and traps the island's inhabitants. In a striking depiction of this, Kirby draws an aerial view of Manhattan, emphasizing its skyscrapers and grid layout, while an Air Force jet passes impotently overhead. Confronted with the disruption of their power base, the FF are temporarily exiled to the margins of the city. In fact, they take they subway and end up on Yancy Street, where they are even assisted by a member of the Yancy Street Gang. The Molecule Man is finally defeated after Reed deduces his one weakness. Sue affirms the villain's role as Reed's doppelganger when she states, "If only we had been given his power! What wonderful things we could do for mankind!" Though she speaks for the group, it is clear that such power could only be managed by the one man who proved he understands it, Reed.

The Molecule Man represents the ultimate anxiety of modernity and the Cold War when he claims, "I hereby nullify every man-made law! I countermand every known rule and regulation! There shall be no law but my will!" The world is absolutely unstable in the most threatening way. The emblem of modernity that previously stabilized the city/nation/free world (the Baxter Building) has been itself rendered unstable and directly menacing. More than this, the world is unstable as the result of the evil designs of a super-powerful dictator they cannot reckon with. It becomes the province of the FF, the super-powerful bastions of democracy, to counter this menace, return the Baxter Building to its rightful place, and restore order. Technology is only a threat in the ideologically wrong hands; the skyscraper is only menacing when it is temporarily wrested from the control of white corporate America. Once that control is reasserted, once hegemony is again back in place, then the city/nation can continue about its business until the next threat to its order erupts and it must once again call upon the FF for help.

\section{The Future is Now, Futurama is Here:}

From Ferriss to Kirby, Manhattan has been a site of perpetual reinscription, an urban palimpsest that seems infinitely open to fantastic re-imaginings. Rem Koolhaas writes that Manhattan is "the product of an unformulated theory, Manhattanism, whose program - to exist in a world totally fabricated by man, i.e., to 
live inside fantasy - was so ambitious that to be realized, it could never be openly stated" (10). The fictional representation of Manhattan in The Fantastic Four corresponds to an equally distorted self-image of America perpetuated within popular culture to, in part, build support for the space race. When the New York World's Fair opened its doors to the public from April 22, 1964 to October 17, 1965, this
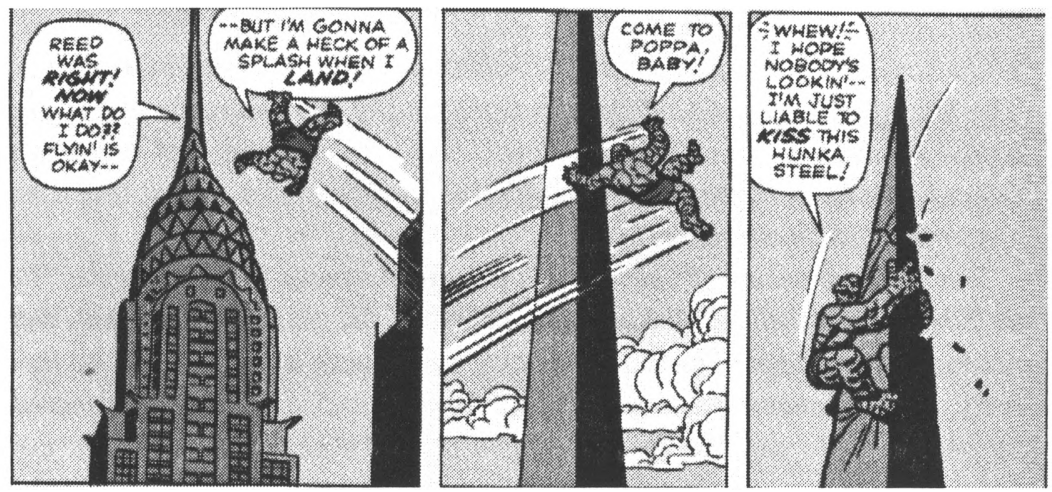

conflation was materially realized. The fair was, at its uncritical core, "all about the promise that science, technology and a free society were the keys to building a better tomorrow" (Cotter and Young 13). The theme of the fair was "Peace Through Understanding" and, based on the emphasis on corporate-sponsored space-themed exhibits, peace would be most easily achieved once General Motors helped the United States build a base on the moon. The fair featured 31 space vehicles "on loan. . . by NASA and the Defense Department" in a pavilion dubbed the U.S. Space Park (Cotter and Young 29). This government-sponsored pavilion equates to the corporate-sponsored exhibits that it stood alongside. Elsewhere fair-goers could see simulations of astronauts walking in space, a radio astronomy dish, and a Cinerama film, entitled To the Moon and Beyond, that played at the Moon Dome, a building whose exterior was a plastic relief map of the moon's surface. However, the most popular attraction was General Motors' "Futurama," which depicted a host of promising American frontiers, including Antarctica, the ocean floor and, principally, the moon. The exhibit ended with a vision of the "City of Tomorrow" that looked strikingly similar to the city the visitors were in, for "cities of the future seemed largely the same as cities of the present, dominated by skyscrapers and highways" (Stern 1050). The fair's inability to contend with the city's present was as telling as this uninspired vision of an urban future. The fair, more than any other before it, was an overwhelmingly corporate enterprise. Its very symbol, a huge steel globe dubbed the "Unisphere" was as much an advertisement for the U.S. Steel Corporation, which funded it, as it was any expression of global harmony. Architectural critic Wolf Von Eckardt fumed at the time that the fair "only reflects, in a billion-dollar surrealist distortion mirror, what huckster greed and hard-sell free enterprise does to us all over the land" (Stern 1031). For many critics the fair was a failure and while it did have 59 million visitors, this number fell well short of its organizers' goals. In short, the fair was a money-loser. 
Some of this can be directly attributed to the fair's inability to address the urban unrest that it placed itself firmly amongst and helped foment. Rental rates for vending spaces were inordinately high, excluding smaller vendors. On the eve of the fair's opening the Congress on Racial Equality threatened a "stall-in" to protest the fair. While this protest did not materialize, there was a demonstration by the CRE to draw attention to what their national director termed "the melancholy contrast between the idealized, fantasy world of the fair and the real world of brutality, prejudice, and violence in which the American negro is forced to live" (Stern 1031). The boundaries of this mock utopia were simply too porous for it to be tenable. It would seem the CRE's claims at least echoed a general lack of enthusiasm for the fair, as President Johnson's opening remarks attracted a crowd less than half the size projected by organizers.

The relative failure of the World's Fair underscores to what degree The Fantastic Four successfully elided social concerns of the era. Lee and Kirby were able to maintain their utopian vision of the city by keeping it further beyond the realm of reality than General Motors' "City of Tomorrow." They ignored contemporary racial issues in a way that the World's Fair could not. For example, the comic book did not feature a major black character, even for a single story, until issue 52 (July 1966). Even then, that character, the Black Panther, is an African chieftain and the story takes place almost entirely in his native country. The boundaries of the white city remain unwavering. There are no African Americans in this world, only Africans, and they are benign people eager to assist the FF in their rhetorical battle for a democracy that only exists in the Kirbian womb of their Manhattan.

What is especially provocative about the FF in the context of the World's Fair is how Lee and Kirby so strongly render the group itself in corporate terms. According to James Oliver Robertson, when corporations appropriated Frontier Mythology at the turn of the century, they appealed "to the older myths of community service and voluntary cooperation" while they "revised individualism and provided an attractive explanation of the rise and ultimate benefit of corporate big business to a rapidly urbanizing, industrializing America" (182). By the 1960s the attributes formerly ascribed to the individual, such as cooperation, opportunity, and success, appeared to be natural characteristics of the corporation (183). Corporations were so successful at incorporating the residual of Frontier Mythology that, according to Robertson, they became "the predominant American models of efficient government. . . They do the work of the entire nation, perhaps of the world. They serve American needs and desires" (183). In the context of the Cold War, an emergent - anxiety about nuclear war and Soviet occupation of space - was addressed by the dominant. This resulted in the incorporation of those fears into the dominant by way of political rhetoric and, most importantly, popular culture. The Fantastic Four is an ideal text in which to examine how that emergent was paired with the residual (Frontier Mythology) by the dominant.

Like a corporation, the FF are linked with American interests and Frontier Mythology and occupy a privileged "super-citizen" status within the nation. Corporations are legally afforded the rights of an individual and they are rhetorically ascribed the characteristics of the heroic individual. The Fantastic Four are treated 
similarly in the comic. Like a corporation, the government allows the FF great leeway in how they operate as an organization and the government often depends on them to help right a listing national ship. The FF are independently funded by Reed's wealth, occupy their own skyscraper headquarters in the heart of Manhattan, and, perhaps most significantly, have their own "corporate" logo, the 4 in a circle. Members of the group wear the logo on their matching uniforms with the exception of the Thing, again indicating his fundamentally class-based difference with the rest of the group. The insignia is also prominently displayed on their flying cars, personal jets, etc. The emblem itself suggests exclusivity in its very form and meaning, the uninterrupted circle that contains and emphasizes the 4 . There is no other group of superheroes like this one - their inherent uniqueness emphasized paradoxically by their matching uniforms. While most other superhero groups are a loose conglomeration of heroes who otherwise operate on their own, the FF are a discrete cohesive unit. The presence of the logo on their uniforms and their equipment further serves to equate the group as a manifestation of corporate enterprise, as another set of tools stamped by the corporation and employed in company service that is ideologically tied with national concerns.

Paul Goldberger maintains that " $[\mathrm{m}]$ oving elements in a city, and in particular the people and their activities, are as important as the stationary physical parts. We are not simply observers of this spectacle, but are ourselves a part of it, on the stage with the other participants" (2). The Fantastic Four are privileged moving elements in the milieu of their comic book, an extension of the immobile icon of their white hegemony, the skyscraper. Those "non-moving" (i.e., grounded) elements of the city, its normal citizens, are more than spectators in that they comprise the great democratic society that the FF exist to defend. The Fantastic Four need New Yorkers as much as they need super villains, for both serve to rhetorically validate their existence and gloss over their un-democratic nature. By association with the national project of the space race, The Fantastic Four is able to articulate a necessity for the superhero in ways not done before in comic books. Linked with a national goal equated with national survival, and intimately connected to the modern skyscrapers of Manhattan, the Fantastic Four are able to mediate the very tensions of modern society that the existence of a Mr. Fantastic, Invisible Girl, Thing, and Human Torch represents. When you constantly marvel at sights in the sky above, you are less likely to notice the metaphoric chains that keep you down. Super-patriots dazzle us, the injustices of our society lost in the shadows cast by floating skyscrapers that block the sun.

\section{NOTES}

'It is worth noting that the Fantastic Four's costumes are said to be composed of "unstable molecules." 


\section{WORKS CITED}

Bender, Thomas and William R. Taylor. "Culture and Architecture: Some Aesthetic Tensions in the Shaping of Modern New York City," in Visions of the Modern City, William Sharpe and Leonard Wallock, eds. Baltimore: The Johns Hopkins UP, 1987.

Bukatman, Scott. "The Boys in the Hoods: A Song of the Urban Superhero," in Matters of Gravity: Special Effects and Supermen in the $20^{\text {th }}$ Century. Durham: Duke UP, 2003.

Cotter, Bill and Bill Young. Images of America: The 1964-1965 New York's World's Fair. Charleston, SC: Arcadia Publishing, 2004.

Golderberger, Paul. The Skyscraper. New York: Alfred A. Knopf, 1986.

Koolhaas, Rem. Delirious New York: A Retroactive Manifesto for Manhattan. New York: The Monacelli, 1994.

Lee, Stan and Jack Kirby. Essential Fantastic Four Vol. 1. New York: Marvel Comics, 2005.

Lee, Stan and Jack Kirby. Essential Fantastic Four Vol. 2. New York: Marvel Comics, 1999.

Lee, Stan and Jack Kirby. The Fantastic Four, 1 Nov. 1961.

---. The Fantastic Four, 2 Jan. 1962.

---. The Fantastic Four, 3 Mar. 1962

---. The Fantastic Four, 4 May 1962.

---. The Fantastic Four, 5 July 1962.

---. The Fantastic Four, 6 Sept. 1962.

---. The Fantastic Four, 7 Oct. 1962.

---. The Fantastic Four, 8 Nov. 1962.

---. The Fantastic Four, 9 Dec. 1962.

---. The Fantastic Four, 11 Feb. 1963.

---. The Fantastic Four, 12 Mar. 1963.

---. The Fantastic Four, 13 Apr. 1963.

---. The Fantastic Four, 15 June 1963.

---. The Fantastic Four, 17 Aug. 1963.

---. The Fantastic Four, 20 Nov. 1963.

---. The Fantastic Four, 21 Dec. 1963.

---. The Fantastic Four, 30 Sept. 1964.

--. The Fantastic Four, 35 Feb. 1965.

---. The Fantastic Four, 49 Apr. 1966.

--- The Fantastic Four, 51 June 1966.

---. The Fantastic Four, 52 July 1966.

McCurdy, Howard E. Space and the American Imagination. Washington, D.C.: Smithsonian Institution Press, 1997.

Nevins, Allan, ed. The Burden and the Glory: The Hopes and Purposes of President Kennedy's Second and Third Years in Office as Revealed in His Public Statements and Addresses. New York: Harper \& Row, 1964.

Robertson, James Oliver. American Myth, American Reality. New York: Hill \& 
Wang, 1980.

Romanyshyn, Robert. Technology as Symptom and Dream. New York:

Routledge, 1989.

Slotkin, Richard. Gunfighter Nation: The Myth of the Frontier in Twentieth Century America. Norman, OK: U of Oklahoma P, 1998.

Spigel, Lynn. Welcome to the Dreamhouse: Popular Media and Postwar Suburbs. Durham: Duke UP, 2001.

Staiger, Janet. "Future Noir: Contemporary Representations of Visionary Cities," in Alien Zone II: The Spaces of Science-Fiction Cinema. Ed. Annette Kuhn. New York: Verso, 1999.

Stern, Robert A., Thomas Mellins, and David Fishman. New York 1960: Architecture and Urbanism Between the Second World War and the Bicentennial. New York: The Monicelli, 1995.

Tichi, Cecelia. Shifting Gears: Technology, Literature, Culture in Modernist America. Chapel Hill: The U of North Carolina P, 1987.

Williams, Raymond. Marxism and Literature. New York: Oxford UP, 1977. 